\title{
Evaluation of the Performance and Microstructure of Ecofriendly Construction Bricks Made with Fly Ash and Residual Rice Husk Ash
}

\author{
Chao-Lung Hwang ${ }^{1}$ and Trong-Phuoc Huynh ${ }^{1,2}$ \\ ${ }^{1}$ Department of Civil and Construction Engineering, National Taiwan University of Science and Technology, No. 43, Section 4, \\ Keelung Road, Taipei 10607, Taiwan \\ ${ }^{2}$ Department of Rural Technology, Can Tho University, Campus II, 3/2 Street, Ninh Kieu District, Can Tho 900000, Vietnam
}

Correspondence should be addressed to Chao-Lung Hwang; mikehwang0102@gmail.com

Received 28 April 2015; Revised 11 June 2015; Accepted 12 July 2015

Academic Editor: Antônio G. B. de Lima

Copyright (C) 2015 C.-L. Hwang and T.-P. Huynh. This is an open access article distributed under the Creative Commons Attribution License, which permits unrestricted use, distribution, and reproduction in any medium, provided the original work is properly cited.

This research presents the engineering performance and the microstructural characterization of ecofriendly construction bricks that were produced using a binder material made from a mixture of class-F fly ash (FA) and residual rice husk ash (RHA). Unground rice husk ash (URHA) was used as a partial fine aggregate substitute (0-40\%). The solid bricks of $220 \times 105 \times 60 \mathrm{~mm}$ in size were prepared by mixing FA and RHA with an alkaline solution and fine aggregates, formed by compressing the mixture in a steel mold under $35 \mathrm{MPa}$ of forming pressure, and then cured at $35^{\circ} \mathrm{C}$ and $50 \%$ relative humidity until the required testing ages. The tests of compressive strength, water absorption, and bulk density were conducted in accordance with relevant Vietnamese standards in order to estimate the effect of the URHA content on the engineering performance of the hardened bricks. Scanning electron microscopy (SEM), X-ray diffraction (XRD), and Fourier transform infrared spectroscopy (FTIR) were performed to determine the microstructure and the phase composition of the brick samples. The results show that properties of these bricks conformed to relevant Vietnamese standards. Therefore, FA and RHA are potential candidate materials for producing ecofriendly construction bricks using geopolymerization technology.

\section{Introduction}

Bricks, a prevalent building material, are used extensively in the construction industry. India and the United States, for example, consume 20 billion and 9 billion bricks each year, respectively $[1,2]$. The annual worldwide production of bricks is about 1.391 trillion units, and demand for bricks is expected to continue rising [3]. In Vietnam, the general demand for bricks is increasing rapidly, and government forecasts show this demand reaching 42 billion units by 2020 . The most common type of bricks used in Vietnam is conventional bricks that are either produced from natural clay and cured by high-temperature kiln firing or produced from ordinary Portland cement (OPC). The production of conventional bricks is energy-intensive, environmentally harmful, and highly pollutant. Both fired-clay bricks and OPC bricks are the major contributors to man-made $\mathrm{CO}_{2}$ greenhouse gas emissions, which are a key contributing factor in global warming and climate change [3,4]. Therefore, the Vietnam Government is currently promoting the gradual replacement of conventional brick supplies with unfired building bricks (UBBs) to protect the environment, reduce the use of OPC, and reduce the mining of clay, which is considered a nonrenewable natural resource.

In recent years, many researchers have studied the potential for using various solid waste materials to produce construction bricks [1,5-8]. Mohan et al. [1] studied the utilization of rice husk ash (RHA) as a partial and a full replacement for clay in bricks. They found that the optimum proportion for (RHA + clay) bricks was 30\% RHA and 70\% clay. These bricks exhibited high compressive strength and low brick weight. Moreover, fully replacing of clay with a mixture of either $40 \%$ RHA, $40 \%$ lime, and $20 \%$ gypsum or $50 \%$ RHA, $30 \%$ lime, and $20 \%$ gypsum gave the highest 
strength values of all mixture proportions. Turgut [5] studied the use of limestone powder, class-C fly ash, and silica fume (SF) only in masonry brick production. Bricks containing $20 \%$ SF delivered the highest compressive strength, while the other properties of this bricks, including flexural strength, density, and water absorption, met the Turkish national standards for load-bearing and nonload-bearing concrete masonry units. Morchhale et al. [6] studied the quality of bricks that were made using a mixture of copper-mine tailings and various amounts of OPC and found that compressive strength and water absorption were positively and negatively associated, respectively, with OPC content. Roy et al. [7] prepared bricks by mixing mill tailings with OPC, black cotton soils, and red soils, respectively. The OPC-tailings bricks were cured in water and the soil-tailings bricks were sun-dried and then fired at high temperatures. The bricks with $20 \%$ OPC and 14 days of water curing were found to be suitable, and the quality of the bricks was assessed in terms of linear shrinkage, water absorption, and compressive strength. Shon et al. [8] studied the utilization of stockpiled circulating fluidized bed combustion ash with type-I cement, lime, classF fly ash (FA), and/or calcium chloride to produce compressed bricks. A compaction pressure of 55.2 MPa was used. These bricks were cured at $20^{\circ} \mathrm{C}$ and $100 \%$ relative humidity for one day prior to air curing at room temperature. The compressive strength of these bricks was satisfactory based on the criterion suggested by Soil Block Home Construction. While the abovementioned methods utilize solid wastes to produce construction bricks, all share the same drawbacks of high energy consumption and high levels of greenhouse gas emissions [3].

Recently, researchers have studied the potential of using geopolymerization technology to produce construction bricks. Geopolymerization uses the natural chemical reaction that occurs between amorphous silica and alumina-rich solids in highly concentrated hydroxide or silicate solutions at ambient or slightly elevated temperatures. This reaction forms a highly stable material called a geopolymer, which has amorphous polymeric structures with interconnected $\mathrm{Si}-$ $\mathrm{O}-\mathrm{Al}-\mathrm{O}-\mathrm{Si}$ bonds [9-16]. The geopolymerization process includes the dissolution of solid aluminosilicate materials in a strong alkaline solution, the formation of silica-alumina oligomers, the polycondensation of the oligomeric species to form inorganic polymeric material, and the bonding of undissolved solid particles in the final geopolymeric structure $[15,16]$. Geopolymers have demonstrated good performance in practical applications. Furthermore, this material provides many advantages, including widespread availability of raw material inputs, rapid development of mechanical strength, good durability, high resistance to acids, excellent adherence to aggregates, the ability to immobilize contaminants, and significantly reduced energy consumption and greenhouse gas emissions during production [16-18]. Freidin [10] studied the production of cementless bricks from FA and bottom ash using a sodium silicate $\left(\mathrm{Na}_{2} \mathrm{SiO}_{3}\right)$ solution as the alkali activator and using different forming pressures to prepare the brick samples. The results showed that the resultant bricks, made using geopolymerization, met the Israeli national standard for conventional cement concrete blocks. Arioz et al. [11] used the geopolymerization of FA to produce geopolymer bricks and used $\mathrm{Na}_{2} \mathrm{SiO}_{3}$ and sodium hydroxide $(\mathrm{NaOH})$ solution as the alkali activators. These bricks were produced using $30 \mathrm{MPa}$ of forming pressure and treated at different temperatures $\left(40-100^{\circ} \mathrm{C}\right)$. They found that the compressive strength of the FA-based geopolymer bricks ranged between 5 and $60 \mathrm{MPa}$ and that the effects of heat-treatment temperature and heat-treatment duration on the density of the bricks were not significant. A. Kumar and S. Kumar [14] studied the production of geopolymer paving blocks using FA and red mud. The blocks that contained $10 \%$ and $20 \%$ red mud met Indian Standard IS-15658, with levels of leached toxic metals within permissible limits.

Agricultural and industrial activities regularly generate massive amounts of FA and RHA [5, 19-23]. These two materials are rich in silica and alumina and thus are potential source materials for the production of geopolymers [24, 25]. Therefore, the primary aim of the present study is to evaluate the potential of producing ecofriendly construction bricks using a combination of RHA and FA, as published research on this binder is limited. The bricks used in the present study were produced using geopolymerization technology. The research systematically investigates the effect of unground rice husk ash (URHA) content on the compressive strength, water absorption, and bulk density of brick samples in order to evaluate the engineering performances of ecofriendly construction bricks containing RHA, FA, and URHA as binders and fine aggregates. Additionally, SEM, XRD, and FTIR are also performed to investigate the reaction products.

\section{Materials and Experimental Methods}

2.1. Materials. A combination of FA and RHA was used as binder material for the preparation of brick samples. The RHA powder was prepared by grinding the URHA in a ceramic ball mill for 2 hours. By the way, the mean particle size of the RHA can be decreased significantly.

Grain size distribution, XRD patterns, and SEM images of raw materials are shown in Figures 1-3, respectively. Table 1 presents the physical and chemical characteristics of these ashes. In this study, URHA and locally available natural sand were used as fine aggregates in the mixtures. The URHA (density 2.1, water absorption capacity $27.6 \%$, and modulus of fineness 2.6), a residual of steam generation process where rice husk pellets were burnt in a steam boiler at temperatures of $700-900^{\circ} \mathrm{C}$, was collected at Saigon Ve Wong Co., Ltd., Ho Chi Minh City, Vietnam. The SEM image of URHA particles is shown in Figure 4 . The natural sand (density 2.6, water absorption capacity $1.4 \%$, and modulus of fineness 3.0 ) was sourced from local quarries. Table 2 shows the sieve analysis and fineness modulus (FM) for both the URHA and the natural sand. A solution of $\mathrm{NaOH}$ and $\mathrm{Na}_{2} \mathrm{SiO}_{3}$ was used as the alkali-activator solution. The $\mathrm{NaOH}$ used was commercial grade and supplied by Formosa Plastics Corporation in white flake forms at $98 \%$ purity. The $\mathrm{NaOH}$ solution was prepared by dissolving the $\mathrm{NaOH}$ flakes in water at the appropriate concentration. The $\mathrm{Na}_{2} \mathrm{SiO}_{3}$ liquid used was commercial grade, which is acquired from Kerry Logistics Company in 


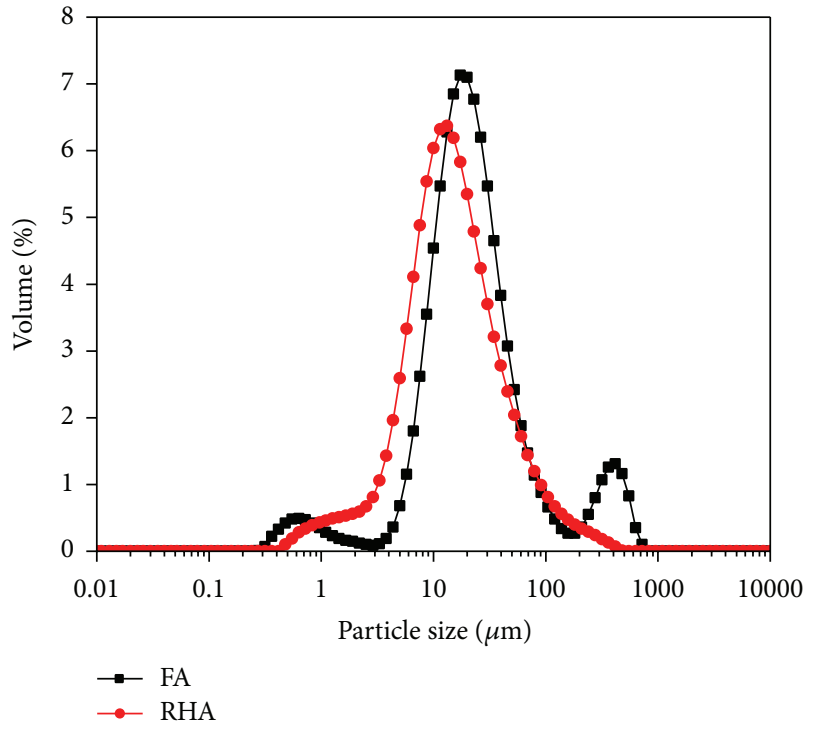

FIGURE 1: Particle size distributions of FA and RHA.

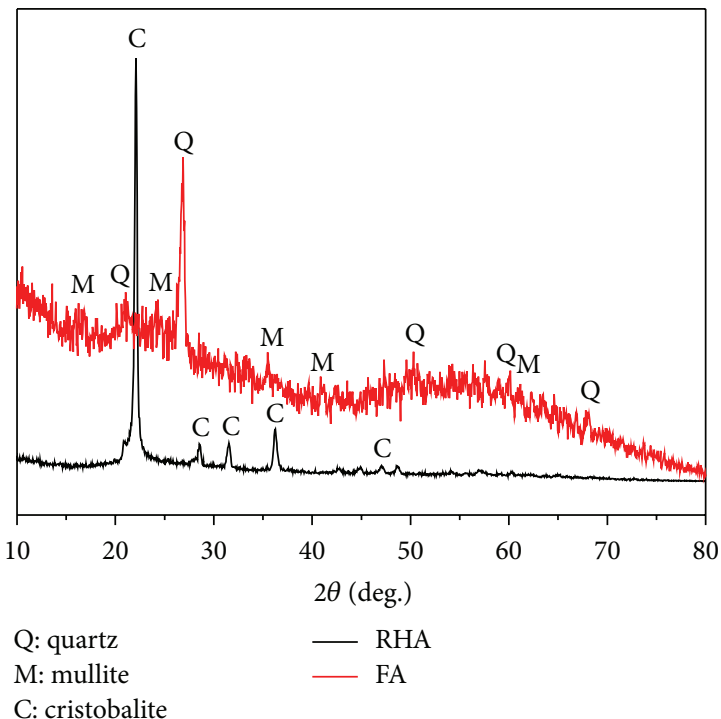

Figure 2: XRD patterns of FA and RHA.

Taiwan, with an approximate $34 \%$ solid content $\left(25.7 \% \mathrm{SiO}_{2}\right.$, 8.26\% $\mathrm{Na}_{2} \mathrm{O}, 66.04 \% \mathrm{H}_{2} \mathrm{O}$, and $\mathrm{SiO}_{2} / \mathrm{Na}_{2} \mathrm{O}=3.11$ ) and $\mathrm{a}$ specific gravity of $1.34 \mathrm{~g} / \mathrm{cm}^{3}$. The liquid was gray in color and highly viscous. The mixing water used was local tap water. All of the materials used in the present study conform to the related ASTM standards.

2.2. Sample Preparation. The $\mathrm{NaOH}$ solution was initially prepared by dissolving the $\mathrm{NaOH}$ flakes in water at a concentration of $10 \mathrm{M}$. The solution was then mixed with the $\mathrm{Na}_{2} \mathrm{SiO}_{3}$ solution and allowed to cool to room temperature. The $\mathrm{SiO}_{2} / \mathrm{Na}_{2} \mathrm{O}$ ratio was 0.81 and the solid-to-liquid ratio was 0.4 . The alkali-activator solution was prepared 24 hours prior to use in order to ensure that the activator component was mixed uniformly. The mixtures were the same in terms
TABLE 1: Physical and chemical analyses of RHA and FA.

\begin{tabular}{lccc}
\hline \multirow{2}{*}{ Items } & \multirow{2}{*}{$\mathrm{RHA}$} & \multicolumn{2}{c}{ Class-F fly ash } \\
& & FA & ASTM C618 \\
\hline Physical properties & & & \\
$\quad$ Specific gravity & 2.18 & 2.08 & - \\
Mean particle size $(\mu \mathrm{m})$ & 15.1 & 21.8 & - \\
Blaine fineness $\left(\mathrm{m}^{2} / \mathrm{kg}\right)$ & 705 & 665 & - \\
Loss on ignition $(\%)$ & 2.67 & 2.01 & - \\
Color & $\mathrm{Black}$ & - & - \\
$\mathrm{Chemical} \mathrm{composition}(\%)$ & & & - \\
$\mathrm{SiO}_{2}(\mathrm{~S})$ & 95.6 & 63.9 & - \\
$\mathrm{Al}_{2} \mathrm{O}_{3}(\mathrm{~A})$ & - & 20.0 & - \\
$\mathrm{Fe}_{2} \mathrm{O}_{3}(\mathrm{~F})$ & 0.24 & 6.64 & - \\
$\mathrm{S}_{+} \mathrm{A}+\mathrm{F}$ & 95.84 & 90.54 & Min: $70 \%$ \\
$\mathrm{CaO}$ & 0.7 & 3.84 & - \\
$\mathrm{MgO}$ & - & 1.25 & Max: $5 \%$ \\
$\mathrm{SO}_{3}$ & 0.15 & 1.32 & - \\
$\mathrm{P}_{2} \mathrm{O}_{5}$ & 0.52 & 0.46 & - \\
$\mathrm{TiO}_{2}$ & 0.02 & 1.22 & - \\
$\mathrm{Na}_{2} \mathrm{O}$ & - & - & - \\
$\mathrm{K}_{2} \mathrm{O}$ & 2.66 & 1.08 & - \\
\hline
\end{tabular}

of the water-to-binder ratio $(w / b=0.51)$ and the applied forming pressure $(P=35 \mathrm{MPa})$. Table 3 shows the mixture proportions by weight used in the brick samples.

Prior to mixing, all of the required materials were prepared according to their respective mixture proportions. A mechanical mixer was used to mix the materials uniformly. FA was added into the mixer and then the mixer was started on a slow rotation speed setting. While the mixer was running, the alkali-activator solution was gradually added to disperse the dry FA powders and produce a viscose paste. The mixer continued to run for 5 minutes on moderate speed. RHA was then added into the mixer and mixing continued for another 5 minutes in order to mix the powders homogeneously into the paste and to achieve complete chemical reactions between the fine-powder materials and the alkaliactivator solution. Finally, the URHA and the natural sand were added to the paste, followed by the water, and allowed to mix for an additional 5 minutes. The finished mixture was poured into a steel mold that measured $220 \times 105 \times$ $60 \mathrm{~mm}$. The compacted specimens were then compressed using a $200 \mathrm{~T}$ computer-controlled automatic compression tester machine under $35 \mathrm{MPa}$ forming pressure to form the solid bricks. Immediately after the compression process, the brick samples were demolded and placed uncovered in an automated temperature controller system for curing at $35^{\circ} \mathrm{C}$ and $50 \%$ relative humidity until the required testing ages were reached.

\subsection{Experimental Methods}

2.3.1. Engineering Performance of Brick Samples. The compressive strength of brick samples was tested at 3, 7, 14, 21, and 28 days of age. Other properties, including water absorption 
TABLE 2: Sieve analyses and fineness modulus (FM) for URHA and natural sand.

\begin{tabular}{lcccc}
\hline & URHA & & Natural sand & $\begin{array}{c}\text { Reference } \\
\text { Percentage of passing }(\%)\end{array}$ \\
Sieve size $(\mathrm{mm})$ & Percentage of passing $(\%)$ & Sieve size $(\mathrm{mm})$ & 97.8 & $95-100$ \\
\hline $4.75(\# 4)$ & 99.3 & $4.75(\# 4)$ & 75.9 & $80-100$ \\
$2.36(\# 8)$ & 84.6 & $2.36(\# 8)$ & 55.3 & $50-85$ \\
$1.18(\# 16)$ & 65.4 & $1.18(\# 16)$ & 40.5 & $25-60$ \\
$0.6(\# 30)$ & 50.8 & $0.6(\# 30)$ & 21.3 & $5-30$ \\
$0.3(\# 50)$ & 29.3 & $0.3(\# 50)$ & 8.3 & $0-10$ \\
$0.15(\# 100)$ & 11.9 & $0.15(\# 100)$ & 3.0 & - \\
\hline FM & 2.6 & FM & \\
\hline
\end{tabular}

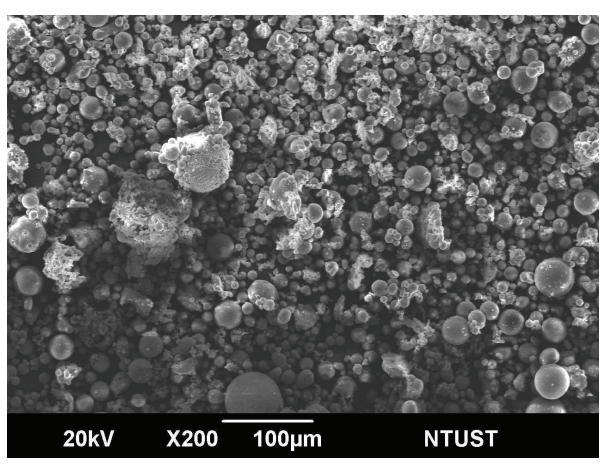

(a)

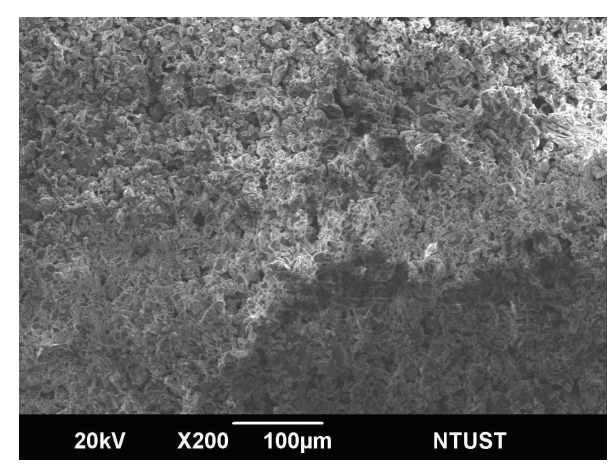

(b)

Figure 3: SEM images of (a) FA and (b) RHA particles.

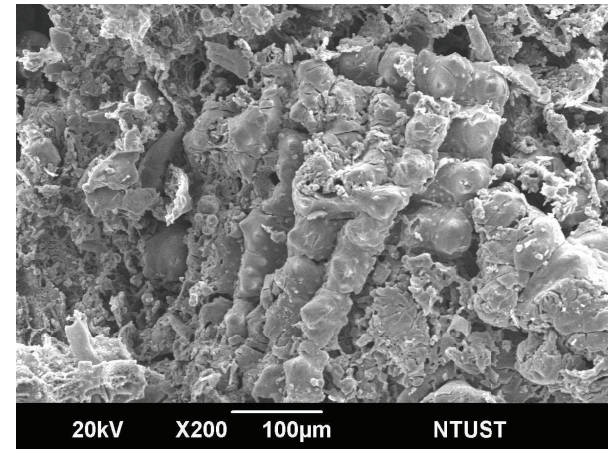

FIGURE 4: SEM image of URHA particles.

TABLE 3: Mixture proportions for the production of ecofriendly construction bricks.

\begin{tabular}{lccccccc}
\hline \multirow{2}{*}{ Sample code } & \multicolumn{7}{c}{ Brick ingredient proportions kg/m } \\
& FA & RHA & Sand & URHA & $\mathrm{NaOH}$ & $\mathrm{Na}_{2} \mathrm{SiO}_{3}$ & Water \\
\hline P35U00 & 370.4 & 246.9 & 1284.4 & - & 182.0 & 49.4 & 81.5 \\
P35U10 & 370.4 & 246.9 & 1156.0 & 128.4 & 182.0 & 49.4 & 81.5 \\
P35U20 & 370.4 & 246.9 & 1027.5 & 256.9 & 182.0 & 49.4 & 81.5 \\
P35U30 & 370.4 & 246.9 & 899.1 & 385.3 & 182.0 & 49.4 & 81.5 \\
P35U40 & 370.4 & 246.9 & 770.6 & 513.8 & 182.0 & 49.4 & 81.5 \\
\hline
\end{tabular}

and bulk density, were measured at 28 days of age. Five brick samples of each mixture proportion were tested, with final results reflecting the average values recorded for each proportion. The preparation and testing of brick samples were conducted in accordance with the official Vietnamese standards. The compressive strength test was performed in accordance with TCVN 6477:2011 [29]. The tests for water absorption and bulk density were conducted in accordance with TCVN 6355:2009 [30].

2.3.2. XRD Analysis. A BRUKER diffractometer model D2-PHASER that used $\mathrm{CuK} \alpha$ radiation was used to obtain X-ray diffractograms of the powdered brick samples. Autosearch/match software was used to aid qualitative analysis. The samples were step-scanned at a rate of $5^{\circ} / \mathrm{min}$, with $2 \theta$ in the range of $10-80^{\circ}$.

2.3.3. FTIR Analysis. A Fourier transform infrared spectrometer model DIGILAB FTS-3500 was used to evaluate the functional group of the samples. Small amounts of potassium bromide $(\mathrm{KBr})$ and powdered brick samples were placed into a mold. A cold-press machine compressed the mold containing the powder together with the $\mathrm{KBr}$ under 4 tons of pressure in order to make pellets for examination. Spectral analysis was performed over the range $4000-400 \mathrm{~cm}^{-1}$.

2.3.4. SEM Observation. The microstructure of the brick samples was observed using an electron beam from a scanning electron microscope JEOL model JSM-6390LV. For SEM analysis, samples were taken from specimens that had 
fractured during compression testing. Prior to making SEM observations, these specimens were mounted into aluminum stubs using double-sided adhesive carbon disks, coated with gold-palladium alloy using an auto fine coater model EMITECH-K550, and vacuum-dried using a beam at $20 \mathrm{kV}$.

\section{Results and Discussion}

3.1. Characterization of FA and RHA. The chemical compositions of original raw materials were determined by X-ray fluorescence analysis (Table 1). The results showed that the FA was composed mainly of $\mathrm{SiO}_{2}(63.9 \%)$ and $\mathrm{Al}_{2} \mathrm{O}_{3}(20.0 \%)$ and that the main constituent of RHA was $\mathrm{SiO}_{2}(95.6 \%)$. As observed from XRD patterns (Figure 2) and SEM images (Figure 3), the FA contained mainly stable crystals of mullite and quartz and the FA particles were mostly smooth and spherical. Further, the RHA contained mainly stable crystals of cristobalite and RHA particles were irregular in shape. Moreover, the RHA particles were significantly smaller than the FA particles (Figure 1).

\subsection{Engineering Performance}

3.2.1. Compressive Strength. Figure 5 shows the development trend for the compressive strength of brick samples at different levels of URHA replacement. Compressive strength increased with curing age due to the positive relationship between curing age and the increase in the pozzolanic reaction $[31,32]$. Thus, increased gelling over time fills more pores inside the bricks and creates an increasingly dense structure, a phenomenon that is in good agreement with previous published studies [33-35]. The brick samples achieved compressive strengths that significantly exceed the strength values required under TCVN 1451:1998 [36]. However, the brick samples prepared with different URHA contents exhibited significant differences in compressive strength development.

The compressive strength of the brick samples in the present study decreased significantly as the amount of the URHA increased (Figure 5). After 28 days of age, the brick samples with $0 \%, 10 \%, 20 \%, 30 \%$, and $40 \%$ URHA replacement levels had respective compressive strengths of $32.9 \mathrm{MPa}$, 25.8 $\mathrm{MPa}, 23.1 \mathrm{MPa}, 21.2 \mathrm{MPa}$, and $20.1 \mathrm{MPa}$. On average, these compressive strengths were, respectively, 21.8\%, 29.9\%, $35.7 \%$, and $38.8 \%$ less than the compressive strength of the URHA-free bricks. As shown by SEM, URHA is made up of highly porous particles (Figure 4). Therefore, the inverse relationship between compressive strength and URHA content may be attributable to the rising volume of capillary pores, which is associated with rising URHA replacement levels. The loss of structural compactness led to lower compressive strengths in bricks with higher levels of URHA content. Moreover, a higher proportion of URHA impacts the rheology of the mixture, resulting in a nonhomogeneous mixture that adversely affects the compressive strength of the resultant bricks. However, the test results clearly show that the brick samples had compressive strength values that met the standard for the highest quality solid construction bricks [36].

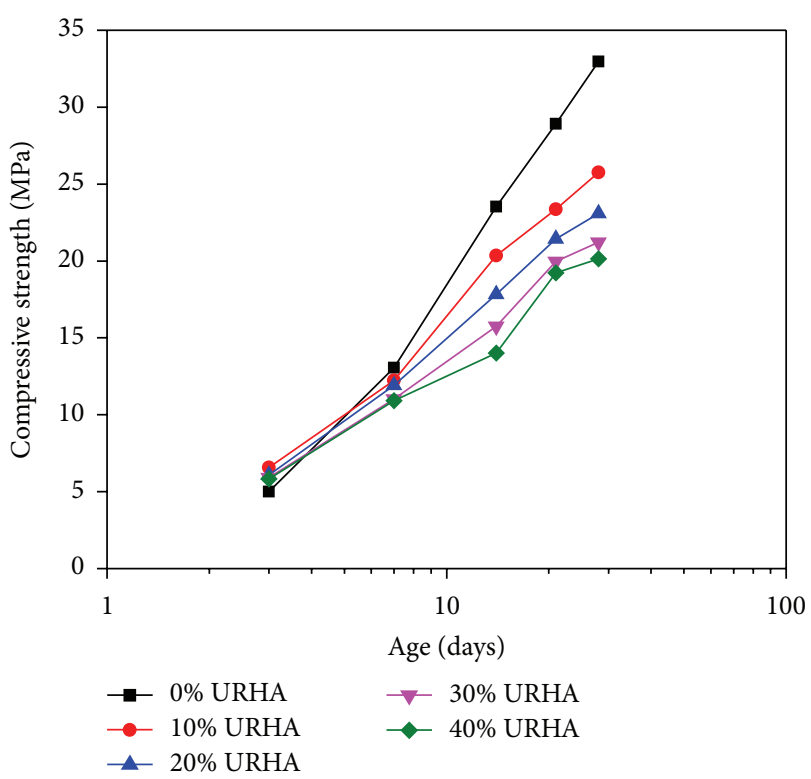

FIGURE 5: Strength development of brick samples at different URHA replacement levels.

3.2.2. Water Absorption. Water absorption is the major factor that affects the durability of construction bricks. Water absorption is the action of surface tension on capillaries that allows for the transport of liquid in porous solids [37, 38]. Figure 6(a) shows the effect of URHA content on the water absorption capacity of brick samples at 28 days of age. Most of the brick samples had water absorption capacities below $16 \%$, which is the level required under TCVN 1451:1998 [36]. Results show that the water absorption rate of the brick structure is closely and negatively associated with the mechanical strength of the bricks.

The results of the water absorption test indicate a proportional relationship between absorption capacity and URHA content. Replacing natural sand with URHA significantly increased the water absorption of brick samples (Figure 6(a)). Therefore, higher URHA replacement levels were associated with higher water absorption rates, which is mainly attributable to the aforementioned significantly more porous nature of URHA particles (Figure 4) in comparison with natural sand. On average, the water absorption levels of the brick samples with 10\%, 20\%,30\%, and 40\% URHA content in the mixture were $10.2 \%, 12.9 \%, 15.7 \%$, and $17.9 \%$, respectively. Further, these brick samples had water absorption levels that were $13.5 \%, 31.6 \%, 43.9 \%$, and $50.8 \%$ higher, respectively, than URHA-free bricks. Moreover, Figure 6(a) reveals that the water absorption capacity of brick samples that contained over 30\% URHA exceeded the limit permitted under TCVN 1451:1998 [36]. The result of the water absorption test is consistent with the aforementioned development trend for brick-sample strength.

3.2.3. Bulk Density. The bulk density value is the key indicator used to classify solid construction bricks. The bulk density correlates inversely with water absorption capacity. 


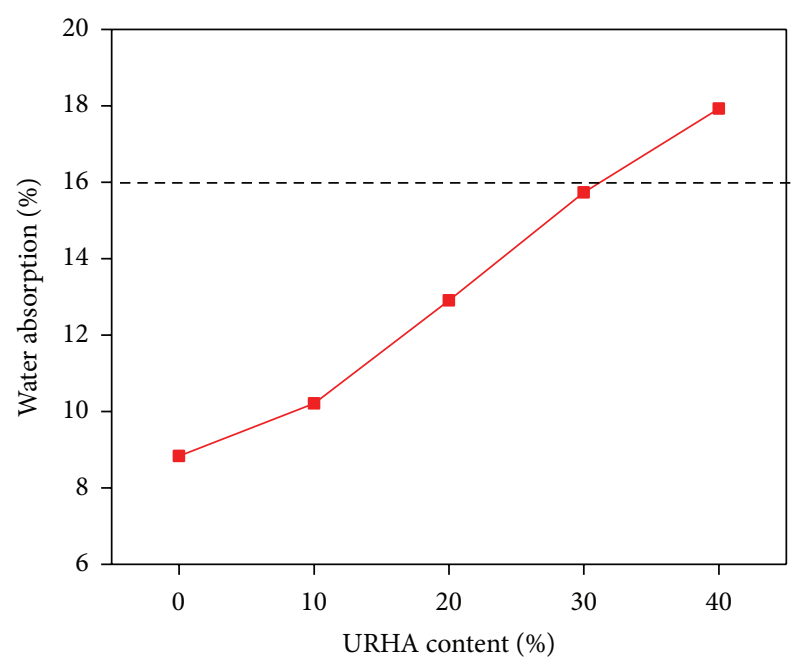

(a)

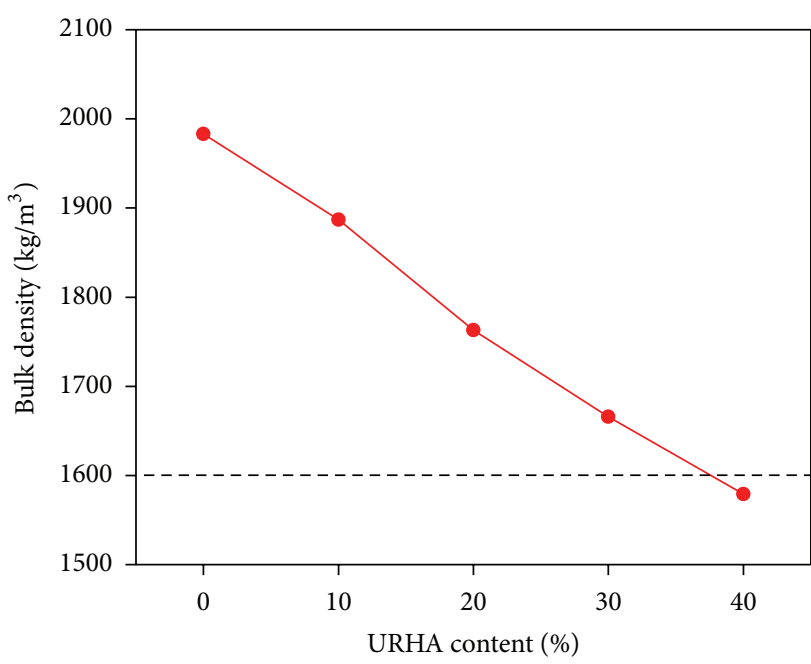

(b)

FIGURE 6: Effect of URHA content on the (a) water absorption and (b) bulk density of bricks.

Figure 6(b) shows the effect of URHA content on the average bulk density of brick samples at 28 days of age. Most samples with and without URHA registered bulk densities higher than $1600 \mathrm{~kg} / \mathrm{m}^{3}$, the minimum density required of solid construction bricks [36].

Adding URHA to the mixture reduced the bulk density of the brick samples significantly (Figure 6(b)). This was mainly due to the much lower specific density of URHA in comparison with natural sand. Thus, the URHA reduced the mass per-unit volume and caused the lower density value. On the other hand, lower bulk density values are associated with lighter brick weight. The results demonstrate that the weight of brick samples fell remarkably at higher URHA content levels. This trend meets expectations due to the increasing number of voids formed within the bricks by the highly porous URHA particles (Figure 4). The bulk density of the bricks was a maximum $1887 \mathrm{~kg} / \mathrm{m}^{3}$ at the level of $10 \%$ URHA replacement and decreased continuously in bricks with URHA contents over $10 \%$. On average, bricks with $10 \%$, $20 \%, 30 \%$, and $40 \%$ URHA replacement levels had bulk densities that were $5.1 \%, 12.5 \%, 19.1 \%$, and $25.6 \%$ less than URHA-free bricks. However, the bulk density values of all brick samples (up to the $40 \%$ URHA replacement level) were all below $1600 \mathrm{~kg} / \mathrm{m}^{3}$, which is the standard requirement for solid construction bricks [36].

\subsection{Microstructural Characterization}

3.3.1. XRD Analysis. Figures 2 and 7 display the XRD patterns of pure FA and RHA powders and brick samples prepared with different levels of URHA replacement, respectively. The pure FA used in the present study consisted mainly of amorphous phase FA with the crystalline phase of predominantly quartz and some weak peaks from mullite (Figure 2). Quartz phases could be detected at $2 \theta$ values of $21.1^{\circ}, 26.9^{\circ}, 50.3^{\circ}$, and $60.1^{\circ}$, whereas mullite phases could be detected at $2 \theta$

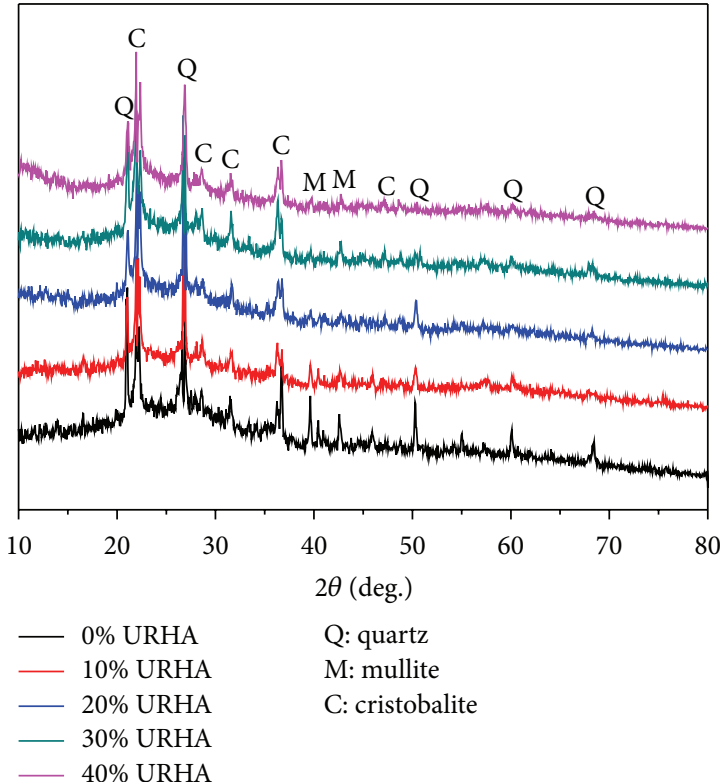

FIGURE 7: XRD patterns of brick samples at various URHA replacement levels.

values of $16.3^{\circ}, 24.3^{\circ}, 35.5^{\circ}$, and $40.9^{\circ}$. No alumina peaks were identified in the XRD pattern, suggesting that the alumina in the FA was mainly in the amorphous phase [25]. The pure RHA used in the present study consisted mainly of crystalline phase RHA with a large amount of silica, which agrees with the compositions shown in Table 1 . The XRD pattern showed sharp reflection peaks, which may be assigned to cristobalite phases, and could be detected at $2 \theta$ values of $22.1^{\circ}, 28.5^{\circ}$, $31.5^{\circ}$, and $36.3^{\circ}$ (Figure 2). The sharp peaks of the cristobalite phases represent the crystallization of silica, which is a major constituent in RHA $[39,40]$. 


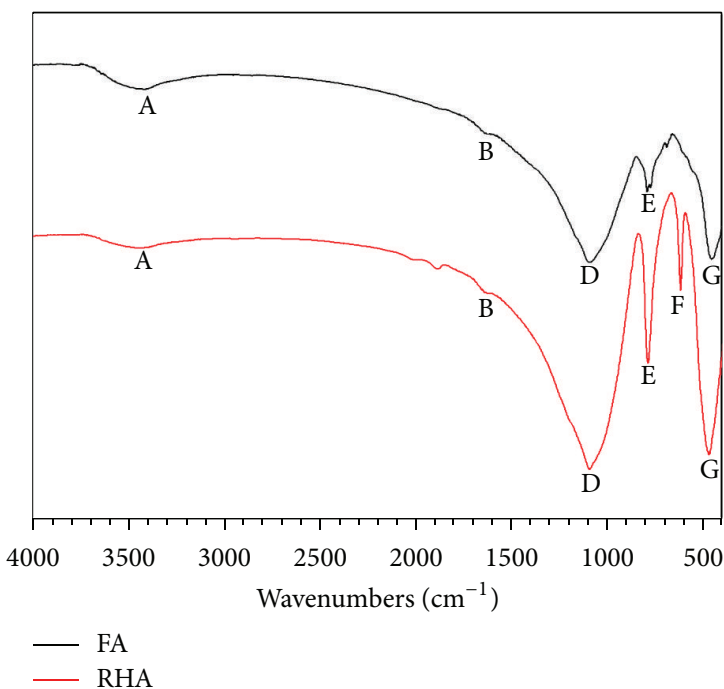

(a)

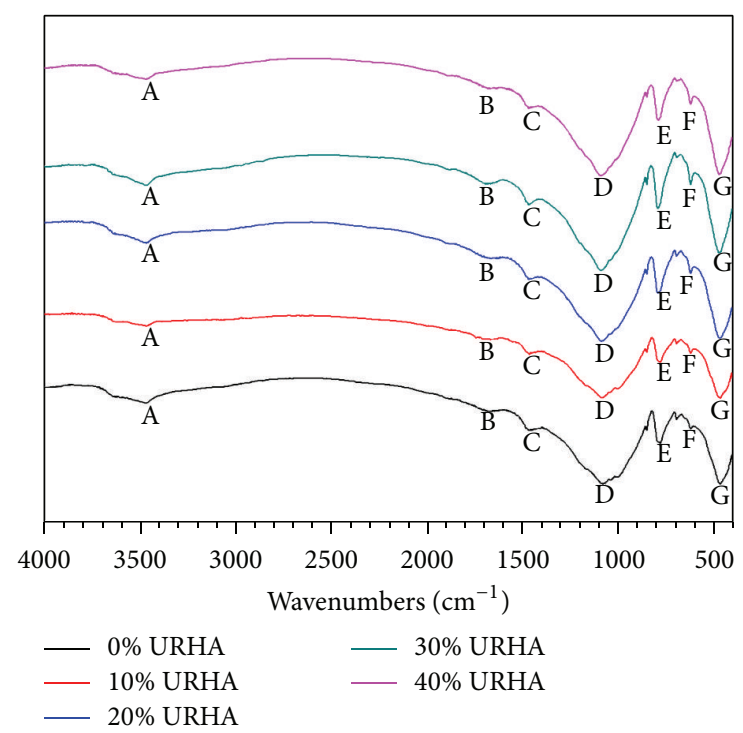

(b)

FIGURE 8: FTIR spectra of (a) the FA and RHA powders and (b) the brick specimens prepared with various URHA replacement levels.

After the geopolymerization process, no new peaks appeared on the XRD patterns of any brick sample (Figure 7) in comparison with the XRD patterns of the parent materials (Figure 2). The major crystalline phases that were presented in the brick samples were quartz, mullite, and cristobalite, which formed the main mineral framework and were responsible for the mechanical strength of the samples [41]. The XRD patterns show that some nondissolvable ingredients in both FA (quartz, mullite) and RHA (cristobalite) still remained in the reaction products. However, these peaks decreased in intensity and the intensity continued to decrease slightly as the amount of URHA in the mixture increased. This indicates that the parent materials were not totally dissolved into the inorganic polymeric materials [42]. A diffuse halo at $2 \theta$ values mostly between $20^{\circ}$ and $40^{\circ}$ was present in all the XRD diffractograms for the brick samples. This is a typical characteristic of geopolymer gels [9]. From the XRD patterns of brick samples, the presence of sharp peaks of quartz and cristobalite, inherited from FA and RHA, respectively, suggests that the crystalline phases had little to no involvement in the geopolymerization process and acted simply as nonreactive fillers in the system [25]. The differences in the crystalline intensities clearly impacted the compressive strength of the brick samples. The obtained strength reduced as the intensity of the crystalline phases declined [42]. This is in good agreement with the compressive strength test results mentioned previously.

3.3.2. FTIR Analysis. Figure 8 shows the FTIR spectra of the FA and RHA powders and of the brick samples prepared with different levels of URHA replacement. Table 4 illustrated the characteristic bands of each spectrum. Significant broad bands were observed at the wave number ranges of $3466-3412 \mathrm{~cm}^{-1}$ (band A) and $1692-1611 \mathrm{~cm}^{-1}$ (band B) for $\mathrm{O}-\mathrm{H}$ stretching and $\mathrm{O}-\mathrm{H}$ bending, respectively. Peaks at the wave number ranges of $1464-1076 \mathrm{~cm}^{-1}$ (bands $C$ and D) and $795-779 \mathrm{~cm}^{-1}$ (band E) were, respectively, attributed to the asymmetric stretching vibration of $\mathrm{Si}-\mathrm{O} / \mathrm{Al}-\mathrm{O}$ and the stretching vibration quartz of $\mathrm{Si}-\mathrm{O}-\mathrm{Si}$. Additionally, the peak centered on $620 \mathrm{~cm}^{-1}$ (band $\mathrm{F}$ ) was associated with the presence of zeolites $[26,28]$. Besides this, the distinct peak centered on $460 \mathrm{~cm}^{-1}$ (band $\mathrm{G}$ ) was ascribed to the $\mathrm{O}-\mathrm{Si}-\mathrm{O}$ bending mode of the $\mathrm{SiO}_{4}$ tetrahedra. This band provides an indication of the degree of "amorphisation" of the material, as the intensity was not associated with the degree of crystallization [28]. The major differences between the FARHA powders and the reaction products were the shifts in the band at $1096 \mathrm{~cm}^{-1}$ to $1091-1078 \mathrm{~cm}^{-1}$ and at around $795 \mathrm{~cm}^{-1}$ to $791-779 \mathrm{~cm}^{-1}$. Taking the sample prepared with $30 \%$ URHA content, as an example, the $1096 \mathrm{~cm}^{-1}$ band moved to $1088 \mathrm{~cm}^{-1}$, and the band at approximately $795 \mathrm{~cm}^{-1}$ moved to $791 \mathrm{~cm}^{-1}$ after the sample reacted with the alkali-activator solution. Thus, both of the bands decreased in intensity. Furthermore, the Si-O-Si position shifted to a frequency that was lower than the original ashes, indicating that a chemical change had occurred in the matrix. These displacements indicate that new products were formed from the reaction between the ashes and the alkali-activator solution (band $\mathrm{C}$ as an example) [28]. This decrease in intensity indicates that the amorphous phase in the ashes was depolymerized to $\mathrm{Si}-\mathrm{O}$ and $\mathrm{Al}-\mathrm{O}$ bonds, while the shifts suggest the polycondensation of these bonds in the alkaline environment [12]. According to Rattanasak and Chindaprasirt [24], Si$\mathrm{O}-\mathrm{Si}$ stretching vibration is more prominent than the $\mathrm{O}-$ $\mathrm{Si}-\mathrm{O}$ bending mode. Therefore, it is logical to use $\mathrm{Si}-\mathrm{O}-\mathrm{Si}$ stretching vibration to assess the degree of geopolymerization. The peak area and peak height are used frequently in the quantitative assessment of geopolymer reactions [24, 27]. The ratios of peak area (AS) and peak height $(H)$ from the FTIR spectra at $\mathrm{Si}-\mathrm{O}-\mathrm{Si}$ stretching vibration for brick 
TABLE 4: FTIR characteristic bands identified in the FA and RHA powders and brick specimens shown in Figure 8.

\begin{tabular}{|c|c|c|c|c|c|c|c|c|}
\hline Band & $\mathrm{FA}\left(\mathrm{cm}^{-1}\right)$ & RHA $\left(\mathrm{cm}^{-1}\right)$ & $\begin{array}{c}\text { P35U00 } \\
\left(\mathrm{cm}^{-1}\right)\end{array}$ & $\begin{array}{c}\text { P35U10 } \\
\left(\mathrm{cm}^{-1}\right)\end{array}$ & $\begin{array}{c}\text { P35U20 } \\
\left(\mathrm{cm}^{-1}\right)\end{array}$ & $\begin{array}{c}\text { P35U30 } \\
\left(\mathrm{cm}^{-1}\right)\end{array}$ & $\begin{array}{c}\text { P35U40 } \\
\left(\mathrm{cm}^{-1}\right)\end{array}$ & Characteristic bands \\
\hline A & 3412 & 3447 & 3464 & 3466 & 3466 & 3466 & 3464 & $\begin{array}{l}\text { O-H stretching }\left(\mathrm{H}_{2} \mathrm{O}\right) \\
{[24,26,27]}\end{array}$ \\
\hline B & 1620 & 1611 & 1692 & 1692 & 1692 & 1692 & 1690 & $\begin{array}{l}\mathrm{O}-\mathrm{H} \text { bending }\left(\mathrm{H}_{2} \mathrm{O}\right) \\
{[24,26,27]}\end{array}$ \\
\hline $\mathrm{C}$ & - & - & 1462 & 1464 & 1462 & 1462 & 1462 & $\begin{array}{l}\mathrm{Si}-\mathrm{O} / \mathrm{Al}-\mathrm{O} \text { stretching } \\
{[24,26]}\end{array}$ \\
\hline $\mathrm{D}$ & 1096 & 1096 & 1078 & 1084 & 1086 & 1088 & 1091 & $\begin{array}{l}\mathrm{Si}-\mathrm{O} / \mathrm{Al}-\mathrm{O} \text { stretching } \\
{[24,27,28]}\end{array}$ \\
\hline $\mathrm{E}$ & 795 & 791 & 779 & 779 & 791 & 791 & 789 & $\begin{array}{l}\mathrm{Si}-\mathrm{O}-\mathrm{Si} \text { stretching quartz } \\
{[26,28]}\end{array}$ \\
\hline $\mathrm{F}$ & - & 621 & 619 & 621 & 619 & 619 & 619 & Zeolites $[26,28]$ \\
\hline G & 459 & 473 & 465 & 465 & 469 & 471 & 471 & $\begin{array}{l}\mathrm{O}-\mathrm{Si}-\mathrm{O} \text { bending }\left(\mathrm{SiO}_{4}\right) \\
{[24,27,28]}\end{array}$ \\
\hline
\end{tabular}

TABLE 5: Ratios of peak area (AS) and peak height $(H)$ from the FTIR spectra of brick specimens at $\mathrm{Si}-\mathrm{O}-\mathrm{Si}$ stretching vibration.

\begin{tabular}{lcccc}
\hline $\begin{array}{l}\text { Sample } \\
\text { code }\end{array}$ & $\begin{array}{c}\text { URHA } \\
\text { content }(\%)\end{array}$ & $\begin{array}{c}\text { Si-O-Si } \\
\text { location } \\
\left(\mathrm{cm}^{-1}\right)\end{array}$ & AS ratio & $H$ ratio \\
\hline P35U00 & 0 & 1078 & 1.000 & 1.000 \\
P35U10 & 10 & 1084 & 0.977 & 0.952 \\
P35U20 & 20 & 1086 & 0.034 & 0.128 \\
P35U30 & 30 & 1088 & 0.031 & 0.115 \\
P35U40 & 40 & 1091 & 0.029 & 0.106 \\
\hline
\end{tabular}

specimens with various levels of URHA are tabulated and presented in Table 5. The value of the AS ratio is usually more accurate than the $H$ value for assessing the degree of geopolymerization [24]. The AS ratios between URHA-free bricks and bricks containing 10\%, 20\%, 30\%, and 40\% URHA are $0.977,0.034,0.031$, and 0.029 , respectively. A $10-40 \%$ increase in URHA content was associated with decreases in the AS ratio, indicating a lower degree of geopolymerization in this range. The $H$ ratio also gave a similar indication of the degree of geopolymerization (Table 5). Both the AS and the $H$ values corresponded very well with the strength results obtained in the present study. The bricks with high AS and $H$ values had high compressive strength values. These results agree with the compressive strength test results mentioned previously.

3.3.3. SEM Observation. Figure 3 shows the micromorphological features of the two original raw materials. The FA was comprised mainly of compact or hollow spheres of different sizes (Figure 3(a)) with a regular and smooth texture. Conversely, the RHA was comprised mainly of particles that were irregularly shaped and porous (Figure 3(b)). Figure 9 displays the microstructure of a representative fractured surface from failed brick samples prepared with various URHA replacement levels. These figures give information on the degree of chemical reaction achieved by the systems.
Generally, the figures indicate that both FA and RHA were stimulated by the alkali-activator solution and that the chemical changes occurred mostly on the edges of the particles. However, a closer observation of Figure 9 shows the presence of partially reacted or unreacted FA particles in brick samples. In addition, more unreacted URHA particles exist at higher levels of URHA replacement. The large amount of unreacted particles indicates a moderate degree of reaction in the system [28].

Figure 9 further shows that the structure of URHA-free bricks (Figure 9(a)) was denser than that of other URHAbrick samples, which is consistent with the development of compressive strength in brick samples (Figure 5). Higher percentages of URHA replacement are associated with a looser brick structure due to the increased amount of unreacted materials. Thus, the resulting microstructure is poor with larger porosity. Moreover, a porous and inhomogeneous microstructure with microcracks and microvoids was clearly observed on the surface of all URHA-brick samples. These cracks may have two possible causes: (1) shrinkage cracks that formed in the process of water evaporation during the curing process and (2) load-induced cracks that formed during compression testing. The two possible causes of the voids in the URHA-brick samples include (1) the residual air bubbles that were introduced into the bricks during the initial mixing and (2) the spaces that were occupied by water and then left as the voids after water evaporation. Because these cracks and voids limit the binding capacity and compressive strength of brick samples, they are likely the main causes of the poor compressive strength of URHA bricks in comparison to URHA-free bricks. He et al. [25] previously reported a similar finding.

\section{Conclusion}

Tests of compressive strength, water absorption, and bulk density and SEM, XRD, and FTIR analyses were conducted to investigate the performance of ecofriendly construction 


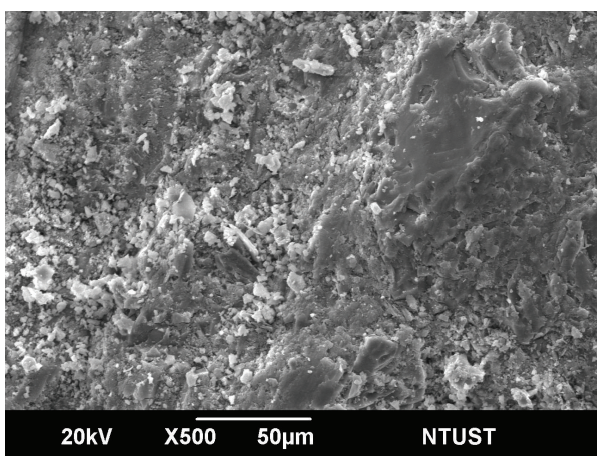

(a) $0 \%$ URHA

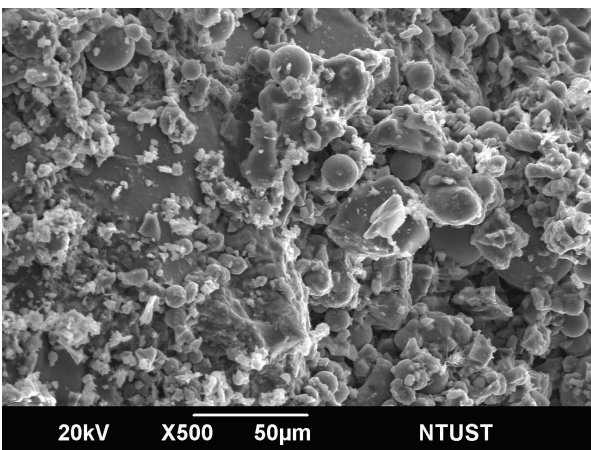

(c) $20 \%$ URHA

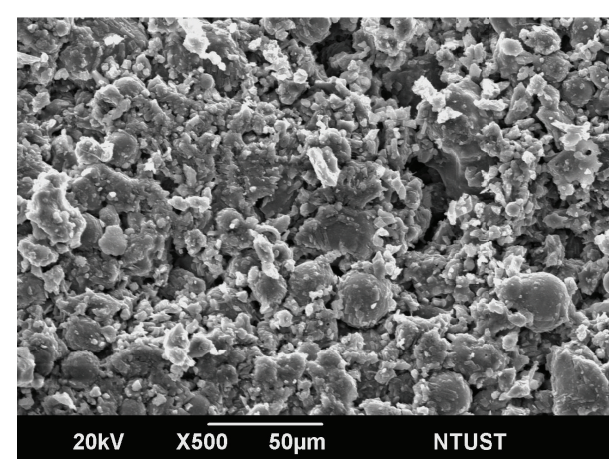

(b) $10 \%$ URHA

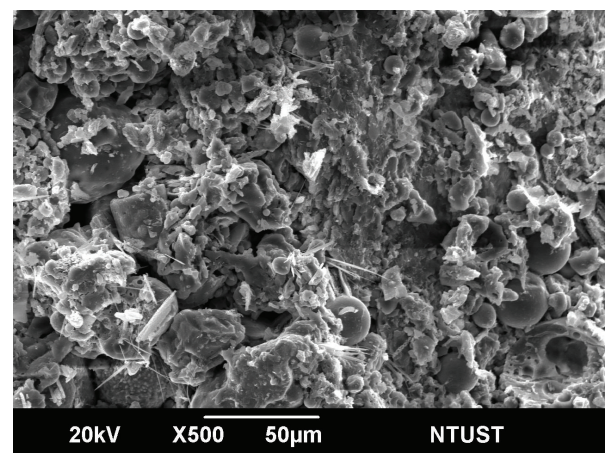

(d) $30 \%$ URHA

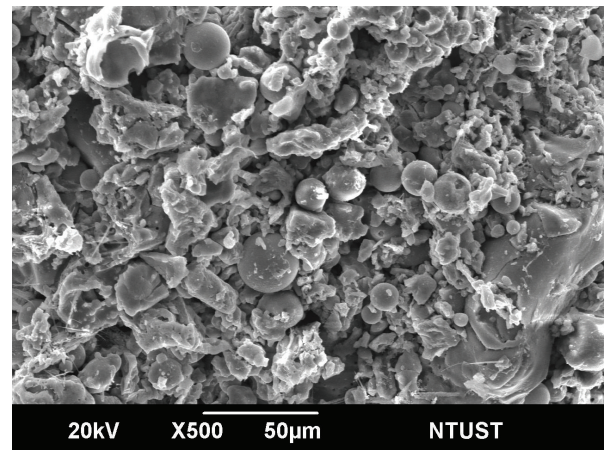

(e) $40 \%$ URHA

FIGURE 9: SEM micrographs of brick samples at various URHA replacement levels.

bricks that were produced using FA and RHA as the binder material. The following conclusions may be drawn from these experimental results.

(i) The brick samples met or exceeded the compressive strength values mandated by TCVN 1451:1998 for the highest quality category of solid construction bricks.

(ii) URHA content affected all of the critical properties of the brick samples. Higher percentages of URHA replacement were associated with decreased compressive strength and bulk density and increased water absorption. The brick samples containing up to $30 \%$ URHA had water absorption rates below $16 \%$ and registered bulk densities above $1600 \mathrm{~kg} / \mathrm{m}^{3}$, which conform to the requirements of TCVN 1451:1998. (iii) Producing ecofriendly construction bricks using FA and RHA as the binder and URHA as a partial fineaggregate replacement is feasible. Using FA, RHA, and URHA to produce bricks not only is cost effective but also facilitates the safe disposal of these solid wastes.

(iv) Bricks with up to 30\% URHA content performed well at an applied forming pressure of $35 \mathrm{MPa}$, a curing temperature of around $35^{\circ} \mathrm{C}$, and a relative humidity of around $50 \%$. These bricks conformed well to the current Vietnamese standard for solid construction bricks.

\section{Conflict of Interests}

The authors declare that there is no conflict of interests regarding the publication of this paper. 


\section{Acknowledgments}

The authors wish to acknowledge the National Taiwan University of Science and Technology (NTUST) for financially supporting this work. Appreciation is also expressed to Hwang's research group and the SUS-CON Research Center, NTUST, for assistance provided during this investigation.

\section{References}

[1] N. V. Mohan, P. V. V. Satyanarayana, and K. S. Rao, "Performance of rice husk ash bricks," International Journal of Engineering Research and Applications, vol. 2, no. 5, pp. 19061910, 2012.

[2] S. Ahmari and L. Zhang, "Production of eco-friendly bricks from copper mine tailings through geopolymerization," Construction and Building Materials, vol. 29, pp. 323-331, 2012.

[3] L. Zhang, "Production of bricks from waste materials-a review," Construction and Building Materials, vol. 47, pp. 643655, 2014.

[4] B. V. V. Reddy and K. S. Jagadish, "Embodied energy of common and alternative building materials and technologies," Energy and Buildings, vol. 35, no. 2, pp. 129-137, 2003.

[5] P. Turgut, "Manufacturing of building bricks without Portland cement," Journal of Cleaner Production, vol. 37, pp. 361-367, 2012.

[6] R. K. Morchhale, N. Ramakrishnan, and N. Dindorkar, "Utilization of copper mine taillings in production of bricks," Journal of the Institution of Engineers, vol. 87, pp. 13-16, 2006.

[7] S. Roy, G. R. Adhikari, and R. N. Gupta, "Use of gold mill taillings in making bricks: a feasibility study," Waste Management \& Research, vol. 25, no. 5, pp. 475-482, 2007.

[8] C.-S. Shon, D. Saylak, and D. G. Zollinger, "Potential use of stockpiled circulating fluidized bed combustion ashes in manufacturing compressed earth bricks," Construction and Building Materials, vol. 23, no. 5, pp. 2062-2071, 2009.

[9] J. Davidovits, "Geopolymers: inorganic polymeric new materials," Journal of Thermal Analysis, vol. 37, no. 8, pp. 1633-1656, 1991.

[10] C. Freidin, "Cementless pressed blocks from waste products of coal-firing power station," Construction and Building Materials, vol. 21, no. 1, pp. 12-18, 2007.

[11] O. Arioz, K. Kilinc, M. Tuncan, A. Tuncan, and T. Kavas, "Physical, mechanical and microstructure properties of F type fly ash based geopolymer bricks produced by pressure forming process," Advances in Science and Technology, vol. 21, pp. 69-74, 2010.

[12] C. Chen, Q. Li, L. Shen, and J. Zhai, "Feasibility of manufacturing geopolymer bricks using circulating fluidized bed combustion bottom ash," Environmental Technology, vol. 33, no. 11, pp. 1313-1321, 2012.

[13] S. Ahmari and L. Zhang, "Utilization of cement kiln dust (CKD) to enhance mine tailings-based geopolymer bricks," Construction and Building Materials, vol. 40, pp. 1002-1011, 2013.

[14] A. Kumar and S. Kumar, "Development of paving blocks from synergistic use of red mud and fly ash using geopolymerization," Construction and Building Materials, vol. 38, pp. 865-871, 2013.

[15] P. Duxson, S. W. Mallicoat, G. C. Lukey, W. M. Kriven, and J. S. J. van Deventer, "The effect of alkali and Si/Al ratio on the development of mechanical properties of metakaolin-based geopolymers," Colloids and Surfaces A: Physicochemical and Engineering Aspects, vol. 292, no. 1, pp. 8-20, 2007.
[16] D. Dimas, I. Giannopoulou, and D. Panias, "Polymerization in sodium silicate solutions: a fundamental process in geopolymerization technology," Journal of Materials Science, vol. 44, no. 14, pp. 3719-3730, 2009.

[17] C. Shi and A. Fernández-Jiménez, "Stabilization/solidification of hazardous and radioactive wastes with alkali-activated cements," Journal of Hazardous Materials, vol. 137, no. 3, pp. 1656-1663, 2006.

[18] J. He, J. Zhang, Y. Yu, and G. Zhang, "The strength and microstructure of two geopolymers derived from metakaolin and red mud-fly ash admixture: a comparative study," Construction and Building Materials, vol. 30, pp. 80-91, 2012.

[19] S. Raut, R. Ralegaonkar, and S. Mandavgane, "Utilization of recycle paper mill residue and rice husk ash in production of light weight bricks," Archives of Civil and Mechanical Engineering, vol. 13, no. 2, pp. 269-275, 2013.

[20] G. R. de Sensale, "Effect of rice-husk ash on durability of cementitious materials," Cement \& Concrete Composites, vol. 32, no. 9, pp. 718-725, 2010.

[21] R. Khan, A. Jabbar, I. Ahmad, W. Khan, A. N. Khan, and J. Mirza, "Reduction in environmental problems using rice-husk ash in concrete," Construction and Building Materials, vol. 30, pp. 360-365, 2012.

[22] G. R. de Sensale, "Strength development of concrete with ricehusk ash," Cement \& Concrete Composites, vol. 28, no. 2, pp. 158160, 2006.

[23] A. Kumar, K. Mohanta, D. Kumar, and O. Parkash, "Properties and industrial applications of rice husk: a review," International Journal of Emerging Technology and Advanced Engineering, vol. 2, no. 10, pp. 86-90, 2012.

[24] U. Rattanasak and P. Chindaprasirt, "Influence of $\mathrm{NaOH}$ solution on the synthesis of fly ash geopolymer," Minerals Engineering, vol. 22, no. 12, pp. 1073-1078, 2009.

[25] J. He, Y. Jie, J. Zhang, Y. Yu, and G. Zhang, "Synthesis and characterization of red mud and rice husk ash-based geopolymer composites," Cement \& Concrete Composites, vol. 37, no. 1, pp. 108-118, 2013.

[26] C. Y. Heah, H. Kamarudin, A. M. Mustafa Al Bakri et al., "Study on solids-to-liquid and alkaline activator ratios on kaolin-based geopolymers," Construction and Building Materials, vol. 35, pp. 912-922, 2012.

[27] P. Chindaprasirt, C. Jaturapitakkul, W. Chalee, and U. Rattanasak, "Comparative study on the characteristics of fly ash and bottom ash geopolymers," Waste Management, vol. 29, no. 2, pp. 539-543, 2009.

[28] A. Fernández-Jiménez and A. Palomo, "Composition and microstructure of alkali activated fly ash binder: effect of the activator," Cement \& Concrete Research, vol. 35, no. 10, pp. 19841992, 2005.

[29] MOC, “Concrete bricks," TCVN 6477:2011, Ministry of Construction, Hanoi, Vietnam, 2011.

[30] TCVN, "Bricks-test methods," TCVN 6355:2009, Ministry of Construction, Hanoi, Vietnam, 2009.

[31] A. Fernández-Jiménez, A. Palomo, and M. Criado, "Microstructure development of alkali-activated fly ash cement: a descriptive model," Cement \& Concrete Research, vol. 35, no. 6, pp. 1204-1209, 2005.

[32] J. Tangpagasit, R. Cheerarot, C. Jaturapitakkul, and K. Kiattikomol, "Packing effect and pozzolanic reaction of fly ash in mortar," Cement and Concrete Research, vol. 35, no. 6, pp. 11451151, 2005. 
[33] C. K. Yip, G. C. Lukey, and J. S. J.van Deventer, “The coexistence of geopolymeric gel and calcium silicate hydrate at the early stage of alkaline activation," Cement and Concrete Research, vol. 35, no. 9, pp. 1688-1697, 2005.

[34] M. H. Zhang, R. Lastra, and V. M. Malhotra, "Rice-husk ash paste and concrete: some aspects of hydration and the microstructure of the interfacial zone between the aggregate and paste," Cement \& Concrete Research, vol. 26, no. 6, pp. 963977, 1996.

[35] R. Zejak, I. Nikolić, D. Blečić, V. Radmilović, and V. Radmilović, "Mechanical and microstructural properties of the fly-ashbased geopolymer paste and mortar," Materiali in Tehnologije, vol. 47, no. 4, pp. 535-540, 2013.

[36] Ministry of Construction, "Solid clay bricks," TCVN 1451:1998, Ministry of Construction, Hanoi, Vietnam, 1998.

[37] D. S. M. Ali Jawaid, "Rice husk ash-lime blended building bricks," International Journal of Earth Sciences and Engineering, vol. 3, no. 2, pp. 302-309, 2010.

[38] I. H. Ling and D. C. L. Teo, "Properties of EPS RHA lightweight concrete bricks under different curing conditions," Construction and Building Materials, vol. 25, no. 8, pp. 3648-3655, 2011.

[39] W. Xu, T. Y. Lo, and S. A. Memon, "Microstructure and reactivity of rich husk ash," Construction and Building Materials, vol. 29, pp. 541-547, 2012.

[40] U. H. Heo, K. Sankar, W. M. Kriven, and S. S. Musil, "Rice husk ash as a silica source in a geopolymer formulation," in Developments in Strategic Materials and Computational Design $V$ : A Collection of Papers Presented at the 38th International Conference on Advanced Ceramics and Composites January 2731, 2014 Daytona Beach, Florida, chapter 7, The American Ceramic Society, 2014.

[41] Y. Chen, Y. Zhang, T. Chen, Y. Zhao, and S. Bao, "Preparation of eco-friendly construction bricks from hematite tailings," Construction and Building Materials, vol. 25, no. 4, pp. 2107-2111, 2011.

[42] Y. M. Liew, H. Kamarudin, A. M. M. Al Bakri et al., "Optimization of solids-to-liquid and alkali activator ratios of calcined kaolin geopolymeric powder," Construction and Building Materials, vol. 37, pp. 440-451, 2012. 

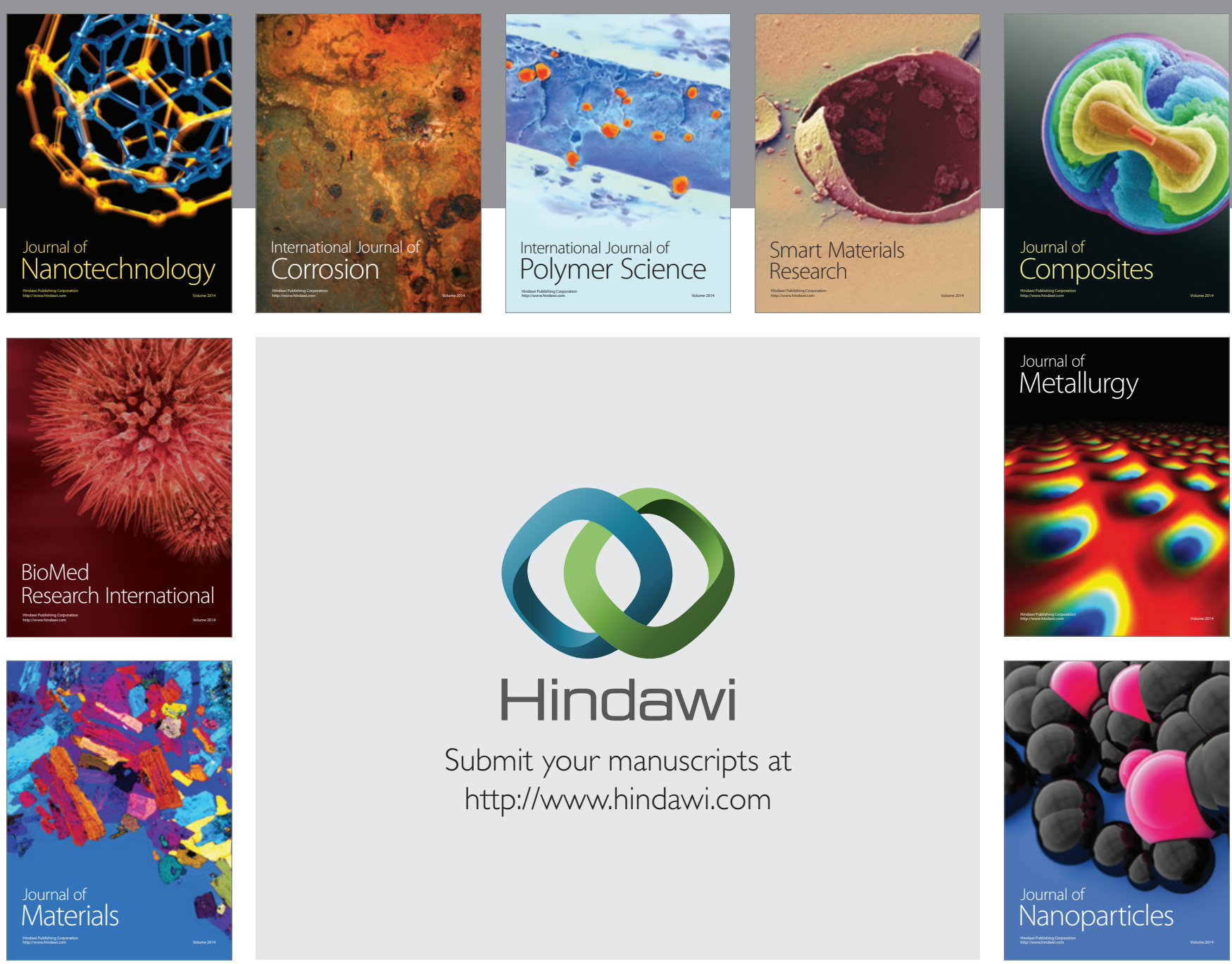

Submit your manuscripts at http://www.hindawi.com
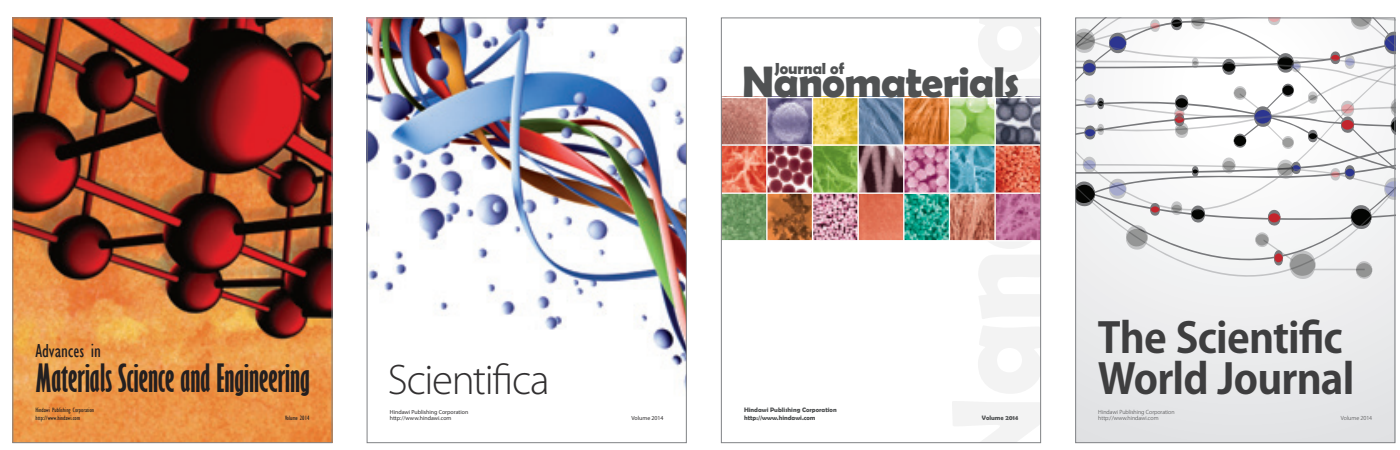

\section{The Scientific World Journal}
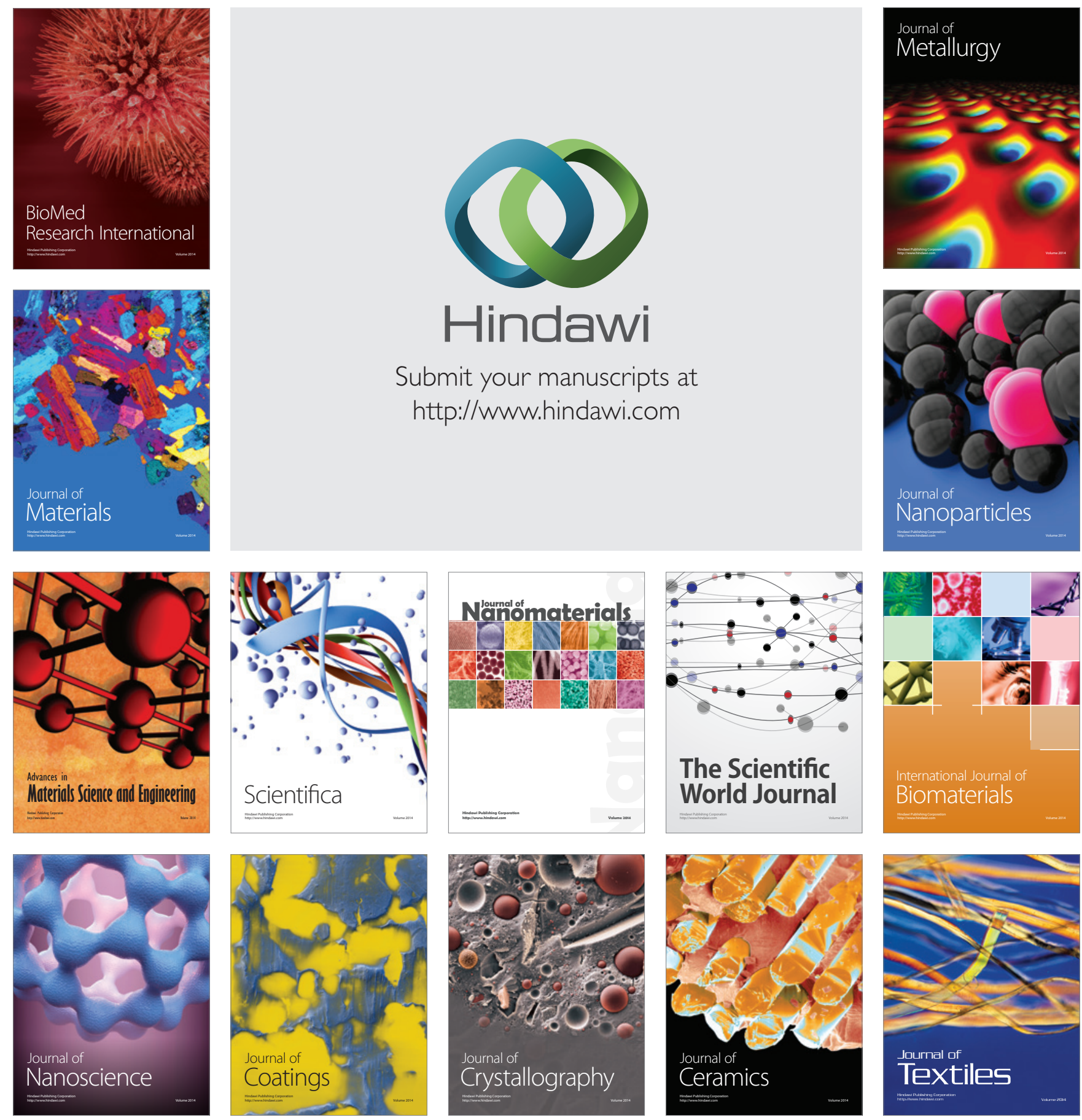